\title{
University Based Research for Social Change: Lessons Learned
}

\author{
Emily Eisenhauer and Bruce Nissen ${ }^{1}$
}

This article examines and analyzes the founding and the history of the Research Institute on Social and Economic Policy (RISEP) at Florida International University. RISEP exists to conduct social science research that brings attention to issues facing low-income communities and working people in the state of Florida and empowers them to participate in public debate and bring about change. The article examines how RISEP's research contributes to building a more just, sustainable, and inclusive society. Topics analyzed include: educating the public, lending legitimacy to hidden problems, assisting low income and disadvantaged communities in proactive engagement in public affairs, provision of a vehicle to assist public campaigns, and framing issues to show underlying structures and attitudes. In its seven years of existence, RISEP has always worked in partnership with workers and communities and made university based research accessible and meaningful to local communities. The authors of the article hope it inspires other academics to do the same. [Article copies available for a fee from The Transformative Studies Institute. E-mail address: journal@transformativestudies.org

Website: http://www.transformativestudies.org (C2011 by The Transformative Studies Institute. All rights reserved.]

KEYWORDS: Academic Research, Social Change, Social Justice, University-Community Collaboration.

\footnotetext{
${ }^{1}$ Bruce Nissen is the Director of Research at the Center for Labor Research and Studies at Florida International University, as well as a sociologist in the university's department of Global and Sociocultural Studies. He is the founder and former director of the Labor Center's Research Institute on Social and Economic Policy (RISEP). Address correspondence to: Bruce Nissen, Florida International University, University Park, Miami, Florida 33199; e-mail: nissenb@fiu.edu.

Emily Eisenhauer is a research associate at RISEP.
} 